\title{
The relationship between the houseboundedness and frailty of community-dwelling elderly persons
}

\author{
Toshiki Katsura ${ }^{1}$, Narumi Abe ${ }^{1}$, Michiko Komata ${ }^{1}$, Mai Ogura $^{1}$, Nobuhito Ishikawa$^{1}$, Akiko Hoshino², \\ Miho Shizawa², Kanae Usui², Eri Yokoyama ${ }^{3}$, and Mayumi Hara ${ }^{3}$ \\ ${ }^{1}$ Division of Preventive Nursing, Department of Human Health Sciences, Graduate School of Medicine Kyoto University, Japan \\ ${ }^{2}$ Division of Community Health Nursing, Graduate of Nursing and Health Sciences Kyoto Prefectural University of Medicine, Japan \\ ${ }^{3}$ Uji City, Kyoto Prefecture, Japan
}

\begin{abstract}
This study aimed to verify whether the incidence of frailty in elderly individuals is higher among those who are housebound than those who are not. This study found no correlation between elderly people's houseboundedeness and physical, mental, social, and overall frailty. However, the Tilburg Frailty Indicator (TFI) frailty score and grip strength value were higher in non-housebound elderly persons than in housebound elderly ones. This suggests that being housebound may lead to frailty. On the other hand, it is thought that individual interaction with family and friends, and lack of anxiety about falls correlates with the prevention of frailty in housebound elderly persons. The results of the study also suggest that the basic checklist may be effective for ascertaining the actual situation of housebound elderly people who may be manifesting frailty.
\end{abstract}

Key words: physical frailty, mental frailty, social frailty, houseboundedness, elderlies, community residents

(J Rural Med 2018; 13(2): 141-150)

\section{Introduction}

The ageing rate in Japan has reached $26.0 \%$, and is expected to increase in future ${ }^{1)}$. As Japan faces the era of the super-aging society, extending the healthy life expectancy

Received: April 23, 2018

Accepted: July 6, 2018

Correspondence: Toshiki Katsura, RN, PHN, Division of Preventive Nursing, Department of Human Health Sciences, Graduate School of Medicine, Kyoto University, 53 Kawabara-cho, Shogoin, Sakyo-ku, Kyoto 606-8507, Japan

E-mail: tkatsura@hs.med.kyoto-u.ac.jp

This is an open-access article distributed under the terms of the Creative Commons Attribution Non-Commercial No Derivatives (by-nc-nd) License $<$ http://creativecommons.org/licenses/by-nc-nd/4.0/>. of elderly persons is an urgent matter.

Being housebound is one of the risk factors for requiring long-term care among healthy elderly persons. It refers to when a person's "range of activities in their daily life is virtually restricted to the indoors" ${ }^{2)}$ indicating a reduction in the spatial range of activity. Japan is unique in that this concept was incorporated long ago into approaches adopted to prevent the elderly from requiring nursing care. Therefore, houseboundedness among elderly people has been associated with an increase in physical activity and cognitive function disorders ${ }^{3}$, reduced social support ${ }^{4}$, and an increased need for nursing care ${ }^{5)}$.

On the other hand, it has been posited that frailty occurs at the stage preceding before elderly people's need for nursing care. Frailty is a dynamic state that can easily result in outcomes such as dysfunction in activities of daily living and ultimately death; the concept encompasses not only physical problems, but also mental and social problems ${ }^{6-8)}$. Therefore, frailty is a threat to the extension of healthy life expectancy among elderly persons and indicates that the individual is in a state necessitating multi-faceted assistance ${ }^{9}$.

In previous studies in Western countries, frailty has been defined in accordance with Fried's ${ }^{10)}$ ideas and measured using the Cardiovascular Health Study index (CHS index $)^{11-13)}$. The CHS index mainly focuses on physical characteristics; therefore, individual's weakened mental or social state cannot be evaluated through this index. Gobbens et al. defined frailty using a complex conceptual model including physical, mental/psychological, and social aspects ${ }^{7}$; the Tilburg Frailty Indicator (TFI) ${ }^{14)}$ is an index based on this model. However, in Japan, frailty is a concept that has not yet gained full consensus. Therefore, to date, there has been little research in Japan evaluating frailty, based on comprehensive definition. Thus, in this research, we investigated 
frailty using the framework of the TFI. Along with comprehensive frailty, we investigated each of its constituents, namely physical, mental, and social frailty.

According to the conceptual model by Gobbens et $a l^{7}$, being housebound is not an aspect of frailty. Therefore, being housebound is thought to represent a situation different from that of frailty. However, the relationship between being housebound and frailty has ostensibly not been fully verified. This study aimed to verify whether the incidence of frailty in elderly individuals is higher among those who are housebound than who are not.

\section{Methods}

\section{Survey target and survey method}

Every year for 3 years from FY2015, a basic checklist was implemented for all elderly residents of different ages, starting from 65 years and the oldest (ages by every other 3 years: 65 years, 68 years to 95 years) in city A in Kyoto Prefecture, who had not applied for nursing care certification. The survey was conducted telephonically, and through post and home visits. The 10,964 respondents to the basic checklist in FY2015 were specified as the cohort. Among this group, respondents who had answered "No" to the question, "Do you leave the house once or more per week?" were defined as housebound and those who answered "Yes" were defined as non-housebound, based on Shinkai et al.'s definition of the former cocept ${ }^{2}$.

The survey region was selected two residential areas with a largest number of housebound elderly persons from the six residential areas of city A, and housebound elderly individuals were randomly extracted from a total of 213 housebound elderly persons, then compared to those randomly selected from a total of 3434 non-housebound elderly persons. These two groups were matched in terms of gender and age ( \pm 3 years), and the data were compared.

The study was explained verbally and in written form to individuals who consented to participation. The study target was 94 elderly individuals comprising 47 housebound and non-housebound elderly persons, irrespectively. Assessments were conducted using a self-reported questionnaire form. The researchers were accompanied by medical professionals from city A when conducting the survey and assessments. The survey period was from July to October 2016.

\section{Surveyed items and assessment methods}

\section{Basic characteristics}

The basic characteristics were age, gender, family structure, employment, residential duration, and educational history. Health status was based on medical history, current medical conditions, body mass index (BMI), blood pres- sure, Tokyo Metropolitan Institute of Gerontology Index of Competence (MTIG-IC) ${ }^{15}$, and lifestyle habits ${ }^{16}$. Blood pressure was measured during home visits.

\section{Frailty}

1) Presence of frailty

The index used for determining frailty is shown in Table 1. If participants subscribed to any aspect of physical, mental, or social frailty listed on the table, then that he or she was deemed to "have overall frailty."

(1) Physical frailty: Shinkai et al. used a modified frailty criterion $^{17)}$, based on the CHS index to determine physical frailty. Individuals to whom three or more of the following five criteria were applicable were identified as "having physical frailty."

a) Weakness was evaluated with grip strength. Grip strength was measured twice, in the order of right, then the left grip; the larger value of each was adopted; the mean value was obtained and this figure was set as grip strength. Based on the determination criteria in a previous study ${ }^{17)}$, a decrease in grip strength was determined as a grip strength of less than $29.0 \mathrm{~kg}$ in men aged 79 years or younger, less than $23.5 \mathrm{~kg}$ in men aged 80 years or older, less than $17.5 \mathrm{~kg}$ in women aged 79 years or younger, and less than $12.5 \mathrm{~kg}$ in women aged 80 years or older.

b) Slowness was evaluated using the 2-step test. The essential standard for slowness is the time taken to walk $5 \mathrm{~m}$. However, these measurements were taken in the subjects' homes. Therefore, since it was difficult to ensure subjects' safety, we used the 2 -step test ${ }^{18)}$, which has a significant positive correlation with the $10 \mathrm{~m}$ walk time. After performing warm-up exercises, the subject took two strides, which could be taken without losing their balance. This was then measured twice under proximal monitoring of the person taking the measurements, and the larger value was adopted. The person's height was also measured. The 2-step value is calculated by dividing the stride by the person's height $(2$-step value $=$ stride $[\mathrm{m}] /$ height $[\mathrm{m}])$. The determination criteria converted the value in a previous study ${ }^{18)}$ to the 2-step value, and "reduction in 2-step value" was set as a 2-step value of less than 0.98 in men aged 79 years or younger, less than 0.86 in men aged 80 years or older, less than 0.91 in women aged 79 years or younger, and less than 0.73 in women aged 80 years or older.

c) Shrinking was set as "weight reduction" based on a weight reduction of $5 \%$ or more in the current body weight compared to the body weight stated on the basic checklist one year ago.

d) Poor endurance and exhaustion were measured through 
Table 1 Subjects

\begin{tabular}{|c|c|c|c|c|}
\hline Items & Categories & $\begin{array}{l}\text { Housebound } \\
n=47\end{array}$ & $\begin{array}{l}\text { Non-housebound } \\
\qquad \mathrm{n}=47\end{array}$ & $p$-value \\
\hline Age & & $76.4 \pm 5.9$ & $76.4 \pm 5.0$ & $-\mid * 1$ \\
\hline \multirow[t]{2}{*}{ Gender } & Male & $21(44.7)$ & $21(44.7)$ & $-\}$ \\
\hline & Female & $26(55.3)$ & $26(55.3)$ & \\
\hline \multirow[t]{2}{*}{ Family structure $^{1)}$} & Living along & $6(12.8)$ & $6(12.8)$ & 0.621 \\
\hline & Living together & $41(87.2)$ & $41(87.2)$ & \\
\hline \multirow[t]{2}{*}{ Emplovment ${ }^{1)}$} & Working & $9(19.1)$ & $8(17.0)$ & 0.500 \\
\hline & No working & $38(80.9)$ & $39(83.0)$ & \\
\hline \multirow[t]{2}{*}{ Medical history ${ }^{1)}$} & Yes & $38(80.9)$ & $42(89.4)$ & 0.193 \\
\hline & No & $9(19.1)$ & $5(10.6)$ & \\
\hline \multirow[t]{2}{*}{ Cirrent medical history $^{11}$} & Yes & $38(80.9)$ & $37(78.7)$ & 0.500 \\
\hline & No & $9(19.1)$ & $10(21.3)$ & \\
\hline $\mathrm{BMI}^{2)}$ & Weight $(\mathrm{kg}) /$ Height $(\mathrm{m})^{2}$ & $23.3 \pm 49.6$ & $22.5 \pm 3.1$ & 0.229 \\
\hline \multirow[t]{2}{*}{ Blood pressure $^{2)}$} & Systolic blood pressure (mmHg) & $136.0 \pm 13.5$ & $134.5 \pm 14.4$ & 0.620 \\
\hline & Diastolic blood pressure $(\mathrm{mmHg})$ & $73.2 \pm 10.3$ & $74.2 \pm 15.2$ & 0.722 \\
\hline \multirow[t]{3}{*}{ Residencial duration ${ }^{3)}$} & $0-9$ years & $6(12.8)$ & $7(14.9)$ & 0.920 \\
\hline & $10-19$ years & $6(12.8)$ & $6(12.8)$ & \\
\hline & 20 years and over & $35(74.5)$ & $35(74.5)$ & \\
\hline \multirow[t]{4}{*}{ Educational background ${ }^{3)}$} & Elementary and junior high school & $14(29.8)$ & $16(34.0)$ & 0.193 \\
\hline & High school & $22(46.8)$ & $18(38.3)$ & \\
\hline & Junior college and vocational school & $5(10.6)$ & $5(10.6)$ & \\
\hline & University and graduate school & $6(12.8)$ & $8(17.0)$ & \\
\hline \multirow[t]{13}{*}{ Basic checklist } & Total score ${ }^{4)} *^{2}$ & $4.9 \pm 2.7$ & $3.3 \pm 2.2$ & 0.005 \\
\hline & Subjects for secondary prevention ${ }^{1)} *^{3}$ & $30(63.8)$ & $28(59.6)$ & 0.416 \\
\hline & Living functional score ${ }^{4)}$ & $3.0 \pm 6.4$ & $0 \pm 0.0$ & 0.121 \\
\hline & & $1.0(0.0-5.0)$ & $0(0.0-3.0)$ & \\
\hline & Hypokinesia $^{1)}$ & $6(12.8)$ & $5(10.6)$ & 0.500 \\
\hline & Physical strength score ${ }^{4)}$ & $1.2 \pm 1.0$ & $1.2 \pm 1.1$ & 0.661 \\
\hline & & $1.0(0.0-4.0)$ & $1(0.0-4.0)$ & \\
\hline & Malnutrition $^{1)}$ & $0(0.0)$ & $1(2.1)$ & 0.500 \\
\hline & Malnutritional score $e^{4)}$ & $0.3 \pm 0.5$ & $0.2 \pm 0.5$ & 0.385 \\
\hline & & $0(0.0-2.0)$ & $0(0.0-2.0)$ & \\
\hline & Low oral function ${ }^{1)}$ & $7(14.9)$ & $6(12.8)$ & 0.500 \\
\hline & Oral functional score ${ }^{4)}$ & $0.5 \pm 0.7$ & $0.5 \pm 0.7$ & 0.937 \\
\hline & & $0(0.0-2.0)$ & $0(0.0-2.0)$ & \\
\hline \multirow{7}{*}{$\begin{array}{l}\text { Tokyo Metropolitan } \\
\text { Institute of Gerontology } \\
\text { Index of Competence } \\
\text { (TMIG-IC) }\end{array}$} & Total score ${ }^{2)}$ & $8.2 \pm 1.4$ & $8 \pm 1.2$ & 0.639 \\
\hline & Instrumental independence (IADL) $^{4}$ & $2.4 \pm 0.9$ & $2.2 \pm 0.6$ & 0.103 \\
\hline & & $2(1.0-5.0)$ & $2(1.0-5.0)$ & \\
\hline & Intellectual activity (Effectance) $)^{4)}$ & $3.5 \pm 0.9$ & $3.6 \pm 0.8$ & 0.377 \\
\hline & & $4(0.0-4.0)$ & $4(0.0-4.0)$ & \\
\hline & Social role $e^{4)}$ & $2.3 \pm 0.8$ & $2.3 \pm 0.6$ & 0.983 \\
\hline & & $2(1.0-4.0)$ & $2(1.0-4.0)$ & \\
\hline \multirow[t]{6}{*}{ Lifestyles (Health practices) } & Good sleeping time $^{1)}(\geq 7$ hours $)$ & $20(42.6)$ & $15(31.9)$ & 0.197 \\
\hline & No smoking ${ }^{1)}$ & $37(78.7)$ & $38(80.9)$ & 0.500 \\
\hline & No drinking ${ }^{1)}$ & $27(57.4)$ & $25(53.2)$ & 0.418 \\
\hline & Having breakfast every day ${ }^{1)}$ & $43(91.5)$ & $46(97.9)$ & 0.181 \\
\hline & No eating between meals ${ }^{1)}$ & $17(36.2)$ & $10(21.3)$ & 0.085 \\
\hline & Appropriate body weight ${ }^{1)}$ & $31(66.0)$ & $34(72.3)$ & 0.328 \\
\hline
\end{tabular}

n (\%) Mean \pm SD. Median (Minimum-Maximum). $*^{1}$ One home-bound and one non-home-bound were matched with both age and gender. ${ }^{2}$ Items on dipression were excluded. ${ }^{3}$ Subjects with only 1 declining functions such as hypokinesia, malnutrition and low oral function, or total scores are $\geq 10 .{ }^{1)}$ Fisher's exact test, ${ }^{2)} \mathrm{t}$ test, ${ }^{3)} \mathrm{X}^{2}$ test, ${ }^{4)}$ Mann-Whitney's U test. 
responses to two questionnaire items, namely, "doing anything is bothersome" and "unable to concentrate on anything"17). Respondents who answered, "more than once or twice a week" were defined as "having exhaustion."

e) Low activity was measured through responses to questions on the frequency of leisure activities involving physical activity and of performing housework ${ }^{17}$. Respondents who answered that they perform leisure activities less than once a week and no housework, that they performed housework, but almost no leisure activities, or that they almost never perform either leisure activities or housework, were defined as "having reduced activity level."

(2) Mental frailty: There is no general scale used in Japan to determine mental frailty; so, mental frailty was determined based on the following mental frailty factors, as set out in the TFI: reduced cognitive function, depressive tendency, and poor stress coping mechanisms. Individuals fulfilling two of the following three were identified as "having mental frailty."

a) The Japanese version of the Montreal Cognitive Assessment (MoCA-J) ${ }^{18)}$ was used to determine reduced cognitive function. Individuals with 25 or less out of 30 points were defined as "having reduced cognitive function."

b) The Japanese Short GDS (GDS-S-J) ${ }^{19)}$ was used to determine depressive tendency. A score of 6 points or higher ${ }^{20)}$ indicated as "having depressive tendency."

c) The rating scale developed by Ozeki was used to measure stress coping function ${ }^{21}$. This scale measures a person's behavior and thought processes in response to the strongest stressor, using 14 items. Individuals who did not achieve the median value of the total score (12 points/14 points) were defined as having "poor stress coping mechanisms."

(3) Social frailty: There is no general scale used in Japan to determine social frailty; so, social frailty was determined with reference to the following social frailty factors set out in the TFI: living alone and social support. Individuals to whom either of the following 2 items were applicable were defined as "having social frailty".

a) A person was defined as living alone when answering "No" to the question "Is there anyone currently living with you?"

b) The Lubben Social Network Scale (LSNS-6-J) ${ }^{22)}$ was used to determine TFI social frailty. The score range was 0 to 30 and a score of less than 12 indicated as social isolation ${ }^{22)}$

2) TFI frailty

The above items only evaluate physical, mental, and social frailty individually. In this study, the TFI was used to determine overall frailty. The TFI frailty index is used to not only determine physical, mental, and social frailty, but also reduced visual acuity, hearing ability, and sense of balance. Reduced visual acuity and hearing ability were applied to respondents who answered "Yes" to the questions "Do you feel you have problems with your vision?" and "Do you feel you have problems with your hearing?". A reduced sense of balance was applicable to respondents who answered "Yes" or "Sometimes" to the question, "Do you feel you have problems with your balance?". The total score was calculated by allocating 1 point for each corresponding item, based on the TFI criteria ${ }^{7}$, and a person with a score of 6 or more was defined as "having TFI frailty."

\section{Basic checklist}

The basic checklist is a self-administered questionnaire used for identifying candidates for secondary prevention work, which is implemented by individual municipalities and is based on the Ministry of Health, Labour and Welfare Community Support project. This questionnaire included 25 items comprising the following seven domains: lifestyle (instrumental activities of daily living (IADL) / social activities), physical strength, nutritional status, oral function, being housebound, cognitive function, and depression risk ${ }^{23}$.

\section{Analysis methods}

The differences between the housebound group and nonhousebound group in terms of the incidence of physical, mental, and social and TFI frailty were verified through the McNemar test, and differences in the subscale scores were verified using the paired t-test.

Fisher's exact test and the Mann-Whitney U test were used to verify differences the housebound group and nonhousebound group with each type of frailty and the groups without frailty in terms of applicable items on the basic checklist. Duplicated items used to determine houseboundedness and frailty were excluded from analysis.

The statistical software IBM SPSS Statistics 22 was used for analysis, and statistical significance was set as less than $5 \%$.

\section{Ethical considerations}

Explanations were provided to the study participants both verbally and in written form regarding the study aims and procedures, handling of personal information, benefits and disadvantages of participating in the study, respect for the participants' voluntary, research funding, compensation for harm to damage, possibility of secondary use of the survey data, and contact details for inquiries about the survey. Participants' willingness to participate in the study was 
Table 2 Physical, mental, and social frailty of housebounded and non-housebounded elderly persons

\begin{tabular}{|c|c|c|c|}
\hline Items of frailty & $\begin{array}{l}\text { Housebound } \\
n=47\end{array}$ & $\begin{array}{l}\text { Non-housebound } \\
\qquad \mathrm{n}=47\end{array}$ & $p$-value \\
\hline Physical frailty $++^{1)^{* 1}}$ & $5(10.6)$ & $4(8.5)$ & 1.000 \\
\hline Deterioration in grip strength $+^{1 *^{* 2}}$ & $20(42.6)$ & $14(29.8)$ & 0.238 \\
\hline Grip strength ${ }^{2)^{* 3}}$ & $22.6 \pm 6.9$ & $25.4 \pm 6.6$ & 0.046 \\
\hline Deterioration in 2 -step test $++^{1)^{* 4}}$ & $4(8.5)$ & $2(4.3)$ & 0.687 \\
\hline 2-step score s)*5 $^{*}$ & $1.19 \pm 0.2$ & $1.26 \pm 0.2$ & 0.120 \\
\hline Weight reduction $+{ }^{1)^{*} 6}$ & $9(19.1)$ & $7(14.9)$ & 0.754 \\
\hline Weight reduction $(\mathrm{Kg})^{2)^{*} 7}$ & $2.5 \pm 8.5$ & $1.8 \pm 7.1$ & 0.473 \\
\hline Poor endurance and exhaustion $+{ }^{1)^{*} 8}$ & $8(17.0)$ & $3(6.4)$ & 0.224 \\
\hline Low activity $+{ }^{1)^{* 9}}$ & $18(38.3)$ & $11(23.4)$ & 0.143 \\
\hline Mental frailty $+{ }^{1)^{*} 10}$ & $21(44.7)$ & $17(36.2)$ & 0.523 \\
\hline Cognitive impairment $+{ }^{1)^{*}} 11$ & $32(68.1)$ & $30(63.8)$ & 0.824 \\
\hline MoCA-J score ${ }^{2)}$ & $22.6 \pm 5.1$ & $23.9 \pm 3.4$ & 0.147 \\
\hline Depression $+{ }^{1)^{*} 12}$ & $12(25.5)$ & $6(12.8)$ & 0.180 \\
\hline GDS-S-J score $+{ }^{2)}$ & $4.0 \pm 3.3$ & $3.0 \pm 2.9$ & 0.183 \\
\hline Poor stress coping ${ }^{1)^{* 13}}$ & $20(42.6)$ & $23(48.9)$ & 0.678 \\
\hline Stress coping score ${ }^{2)}$ & $23.0 \pm 8.3$ & $21.3 \pm 7.3$ & 0.284 \\
\hline Social frailty $+{ }^{1)^{*} 14}$ & $17(36.2)$ & $15(31.9)$ & 0.815 \\
\hline Living alone ${ }^{1)}$ & $6(12.8)$ & $6(12.8)$ & 1.000 \\
\hline Isolation $+{ }^{1)^{* 15}}$ & $14(29.8)$ & $9(19.1)$ & 0.359 \\
\hline LSNS-6-J score & $15.6 \pm 7.1$ & $17.3 \pm 6.2$ & 0.221 \\
\hline Overall frailty $+{ }^{* 16}$ & $29(61.7)$ & $26(55.3)$ & 0.345 \\
\hline TFI frailty $+{ }^{1)^{*} 17}$ & $18(38.3)$ & $13(27.7)$ & 0.359 \\
\hline Frailty score ${ }^{2)^{*} 18}$ & $4.7 \pm 2.3$ & $3.6 \pm 2.1$ & 0.019 \\
\hline
\end{tabular}

One housebound and one non-housebound were pairly matched with age and gender. ${ }^{1)}$ McNemar test, ${ }^{2)}$ Paired t-test.

${ }^{*}$ Physical frailty + : more than 3 items among 5 sub-items of physical frailty.

${ }^{* 2}$ Deteriolation in grip power + : grip power; male $(\leq 79$ years old $)<29.0 \mathrm{~kg},(\geq 80$ years old $)<23.5 \mathrm{~kg}$, female $(\leq 79$ years old $)<17.5 \mathrm{~kg},(\geq 80$ years old $)<12.5 \mathrm{~kg}$.

${ }^{* 3}$ Grip power was measured 2 times, respectively, on the right and the left hand, and average grip power was calculated using the higher value of the right and left hand.

${ }^{* 4}$ Deteriolation in 2 -step test $+:$-step score; male $(\leq 79$ years old $)<0.98,(\geq 80$ years old $)<0.86$, female $(\leq 79$ years old $)<0.9,(\geq 80$ years old $)<0.73 \mathrm{~kg}$.

${ }^{* 5}$ 2-step score $=$ maximum 2-step $(\mathrm{m}) /$ height $(\mathrm{m})$. Maximum 2-step score is the highest that measures.

${ }^{* 6}$ Weight reduction + : Weight reduction is $5 \%$ loss or more than weight of 1 year ago.

${ }^{* 7}$ Weight reduction score $(\mathrm{kg})=$ weight of 1 year ago $(\mathrm{kg})$ - weight at home visit $(\mathrm{kg})$.

"8 Poor endurance and exhaustion: responses to two items "doing anything is bothersome" and "unable to concentrate on anything", of a questionnaire. Respondents who answered "more than once or twice a week' were defined as "having exhaustion".

*9 Low activity +: Respondents who answered that they perform leisure activities less than once a week and no housework, or that they perform housework, but almost no leisure activities, or that they almost never perform either, leisure activities or housework were defined as "having reduced activity level".

${ }^{* 10}$ Mental frailty +: mental frailty was determined based on the mental frailty factors set out in the TFI: reduced cognitive function, depressive tendency, and poor stress coping mechanisms. Individuals fulfilling to 2 of the following 3 were determined as "having mental frailty".

${ }^{* 11}$ Cognitive impairment +: Individuals with 25 or less out of 30 points of MoCA-J were defined as "having reduced cognitive function".

${ }^{* 12}$ Depression +: A score of 6 points or higher of GDS-J was defined as "having depressive tendency".

${ }^{* 13}$ Poor stress coping +: individuals who did not achieve the median value of the total score (12 points/14 points) were defined as having "poor stress coping mechanisms".

${ }^{* 14}$ Social frailty +: living alone and social support. Individuals to whom to either of the following 2 of items were applicable were defined as "having social frailty".

${ }^{* 15}$ Isolation +: The score range was 0 to 30 and a score of less than 12 of LSNS-6-J was determined as social isolation.

${ }^{* 16}$ Overall frailty +: If the individual subscribed to any aspect of physical, mental, or social frailty, then that person was deemed to "have overall frailty".

${ }^{* 17}$ TFI frailty +: The total score was calculated by allocating 1 point for each corresponding item based on the TFI criteria, and a person with a score of 6 or more was defined as "having TFI frailty".

${ }^{* 18}$ The total score was calculated by allocating 1 point for each corresponding item based on the TFI criteria. 
Table 3 The relationship between the basic checklist and the frailty of housebound elderly persons*

\begin{tabular}{|c|c|c|c|c|c|c|}
\hline \multirow[b]{2}{*}{ Items } & \multicolumn{3}{|c|}{ Physical frailty } & \multicolumn{3}{|c|}{ Mental frailty } \\
\hline & $\begin{array}{c}\text { Frail } \\
n=5\end{array}$ & $\begin{array}{c}\text { Non-frail } \\
n=42\end{array}$ & $p$-value & $\begin{array}{l}\text { Frail } \\
\mathrm{n}=21\end{array}$ & $\begin{array}{c}\text { Non-frail } \\
n=26\end{array}$ & $p$-value \\
\hline \multicolumn{7}{|l|}{ Lifestyle (IADL/Social activities) } \\
\hline Do you go out by bus or train by yourself ? $?^{1)}$ & $2(40.0)$ & $2(4.8)$ & 0.285 & $7(33.3)$ & $3(11.5)$ & 0.073 \\
\hline Do you go shopping to buy daily necessities by yourself ?') & $0(0.0)$ & $6(14.3)$ & 0.489 & $3(14.3)$ & $3(11.5)$ & 0.558 \\
\hline Do you manage your own deposits and savings at the bank $?^{1)}$ & $1(20.0)$ & $10(23.8)$ & 0.668 & $6(28.6)$ & $5(19.2)$ & 0.341 \\
\hline Do you sometimes visit your friends ? ${ }^{1)}$ & $4(80.0)$ & $15(35.7)$ & 0.078 & $12(57.1)$ & $7(26.9)$ & 0.036 \\
\hline Do you turn to your family or friends for advice $?^{1)}$ & $3(60.0)$ & $12(28.6)$ & 0.178 & $10(47.6)$ & $5(19.2)$ & 0.039 \\
\hline \multicolumn{7}{|l|}{ Physical strength } \\
\hline Do you normally climb stairs without using handrail or wall for support ? $?^{1)}$ & $4(80.0)$ & $15(35.7)$ & 0.078 & $9(42.9)$ & $10(38.5)$ & 0.497 \\
\hline Do you normally stand up from a chair without any aids ? ${ }^{1)}$ & $1(20.0)$ & $5(11.9)$ & 0.511 & $3(14.3)$ & $3(11.5)$ & 0.558 \\
\hline Do you normally walk continuously for $15 \mathrm{~min} ?^{1)}$ & $0(0.0)$ & $7(16.7)$ & 0.429 & $2(9.5)$ & $5(19.2)$ & 0.307 \\
\hline Have you experienced a fall in the past year? & $1(20.0)$ & $8(19.0)$ & 0.673 & $2(9.5)$ & $7(26.9)$ & 0.128 \\
\hline Do you have a fear of falling while walking? & $3(60.0)$ & $14(33.3)$ & 0.243 & $12(57.1)$ & $5(19.2)$ & 0.008 \\
\hline \multicolumn{7}{|l|}{ Malnutritional status/Oral function } \\
\hline Have you lost $2 \mathrm{~kg}$ or more in the past 6 months? & $2(40.0)$ & $9(21.4)$ & 0.332 & $5(23.8)$ & $6(23.1)$ & 0.610 \\
\hline Do you have any difficulties eating tough foods compared to 6 months? & $1(20.0)$ & $9(21.4)$ & 0.715 & $7(33.3)$ & $3(11.5)$ & 0.073 \\
\hline Have you choked on your tea or soup recently? & $1(20.0)$ & $9(21.4)$ & 0.715 & $5(23.8)$ & $5(19.2)$ & 0.488 \\
\hline Do you often experience having a dry mouth? & $1(20.0)$ & $4(9.5)$ & 0.445 & $2(9.5)$ & $3(11.5)$ & 0.603 \\
\hline \multicolumn{7}{|l|}{ Socialization/Cognitive function } \\
\hline Do you go out less frequently compared to last year? & $3(60.0)$ & $21(50.0)$ & 0.521 & $14(66.7)$ & $10(38.5)$ & 0.051 \\
\hline Do your family or your friends point out your memory loss? & $1(20.0)$ & $10(23.8)$ & 0.668 & $6(28.6)$ & $5(19.2)$ & 0.341 \\
\hline Do you make a call by looking up phone numbers ? ${ }^{1)}$ & $1(20.0)$ & $5(11.9)$ & 0.511 & $3(14.3)$ & $3(11.5)$ & 0.558 \\
\hline Do you find yourself not knowing today's date? & $2(40.0)$ & $12(28.6)$ & 0.472 & $5(23.8)$ & $9(34.6)$ & 0.316 \\
\hline \multirow[t]{2}{*}{ Lifestyle score (IADL/Social activities) } & $2.0 \pm 1.6$ & $1.2 \pm 1.3$ & 0.222 & $1.8 \pm 1.2$ & $0.9 \pm 1.3$ & 0.008 \\
\hline & $2.0(0-4)$ & $1.0(0-5)$ & & $2.0(0-4)$ & $0.0(0-5)$ & \\
\hline \multirow[t]{2}{*}{ Physical strength score } & $1.8 \pm 1.3$ & $1.2 \pm 0.9$ & 0.176 & $1.3 \pm 1.0$ & $1.2 \pm 1.0$ & 0.428 \\
\hline & $2.0(0-3)$ & $1.0(0-4)$ & & $1.0(0-3)$ & $1.0(0-4)$ & \\
\hline \multirow[t]{2}{*}{ Nutrition score and oral function score } & $1.0 \pm 1.2$ & $0.7 \pm 0.8$ & 0.502 & $0.9 \pm 0.9$ & $0.7 \pm 0.7$ & 0.344 \\
\hline & $1.0(0-3)$ & $1.0(0-2)$ & & $1.0(0-3)$ & $0.5(0-2)$ & \\
\hline \multirow[t]{2}{*}{ Cognitive function score } & $0.8 \pm 0.8$ & $0.6 \pm 0.7$ & 0.625 & $0.7 \pm 0.9$ & $0.7 \pm 0.5$ & 0.580 \\
\hline & $1.0(0-2)$ & $1.0(0-3)$ & & $0.0(0-3)$ & $1.0(0-1)$ & \\
\hline
\end{tabular}

n (\%), Mean \pm SD, Median (Minimum - Maximum). Fisher's exact test, Mann-Whitney's U test. Participants respond by answering "Yes"or "No". Questions which duplicate both frailty and houseboundedness are removed. Each response indicative of the potential need for preventive care receives a point; this might be a "Yes" to a "negative" question or a "No" to a "positive" question. TFI frailty: Tilburg Frailty Indicator frailty.

confirmed with their signature on the consent form. This study was implemented after receiving approval from the ethics committee of the Graduate School of Medicine and Faculty of Medicine, Kyoto University and Kyoto University Hospital doctors (Approval No. R0574).

\section{Results}

\section{Subject characteristics}

The characteristics of the housebound group $(\mathrm{n}=47$; men; $\mathrm{n}=21$, women; $\mathrm{n}=26$ ) and the non-housebound group $(\mathrm{n}=47$; men; $\mathrm{n}=21$, women; $\mathrm{n}=26$ ) are shown in Table 1 . Of the 97 subjects who participated in the home visit survey, $94(96.9 \%)$ were included in the analysis (3 who withdrew midway were excluded).

The total score for the basic checklist was higher for the housebound than the non-housebound group, and there were few people participating in horizontal organizations.

Frailty-related characteristics of the housebound and nonhousebound groups

The frailty-related characteristics of the housebound and non-housebound groups are shown in Table 2.

1) Overall frailty

There were no significant differences between the housebound and non-housebound groups for people with frailty.

1-1) Physical frailty: There were no significant differences between the housebound and non-housebound with 


\begin{tabular}{|c|c|c|c|c|c|c|c|c|}
\hline \multicolumn{3}{|c|}{ Social frailty } & \multicolumn{3}{|c|}{ Overall frailty } & \multicolumn{3}{|c|}{ TFI (Tilburg Frailty Indicator) frailty } \\
\hline $\begin{array}{l}\text { Frail } \\
\mathrm{n}=17\end{array}$ & $\begin{array}{c}\text { Non-frail } \\
n=30\end{array}$ & $p$-value & $\begin{array}{l}\text { Frail } \\
\mathrm{n}=28\end{array}$ & $\begin{array}{c}\text { Non-frail } \\
n=19\end{array}$ & $p$-value & $\begin{array}{l}\text { Frail } \\
\mathrm{n}=18\end{array}$ & $\begin{array}{c}\text { Non-frail } \\
\mathrm{n}=29\end{array}$ & $p$-value \\
\hline $5(29.4)$ & $5(16.7)$ & 0.253 & $8(28.6)$ & $2(10.5)$ & 0.131 & $7(38.9)$ & $3(10.3)$ & 0.026 \\
\hline $0(0.0)$ & $6(20.0)$ & 0.055 & $3(10.7)$ & $3(15.8)$ & 0.465 & $3(16.7)$ & $3(10.3)$ & 0.418 \\
\hline $3(17.6)$ & $8(26.7)$ & 0.373 & $6(21.4)$ & $5(26.3)$ & 0.480 & $3(16.7)$ & $8(27.6)$ & 0.312 \\
\hline $8(47.1)$ & $11(36.7)$ & 0.347 & $15(53.6)$ & $4(21.1)$ & 0.026 & $11(61.1)$ & $8(27.6)$ & 0.024 \\
\hline $10(58.8)$ & $5(16.7)$ & 0.004 & $12(42.9)$ & $3(15.8)$ & 0.049 & $9(50.0)$ & $6(20.7)$ & 0.039 \\
\hline $7(41.2)$ & $12(40.0)$ & 0.589 & $14(50.0)$ & $5(26.3)$ & 0.092 & $8(44.4)$ & $11(37.9)$ & 0.444 \\
\hline $2(11.8)$ & $4(13.3)$ & 0.628 & $4(14.3)$ & $2(10.5)$ & 0.535 & $4(22.2)$ & $2(6.9)$ & 0.141 \\
\hline $0(0.0)$ & $7(23.3)$ & 0.032 & $2(7.1)$ & $5(26.3)$ & 0.083 & $1(5.6)$ & $6(20.7)$ & 0.161 \\
\hline $3(17.6)$ & $6(20.0)$ & 0.583 & $4(14.3)$ & $5(26.3)$ & 0.476 & $4(22.2)$ & $5(17.2)$ & 0.476 \\
\hline $10(58.8)$ & $7(23.3)$ & 0.017 & $14(50.0)$ & $3(15.8)$ & 0.017 & $11(61.1)$ & $6(20.7)$ & 0.006 \\
\hline $5(29.4)$ & $6(20.0)$ & 0.349 & $8(28.6)$ & $3(15.8)$ & 0.256 & $4(22.2)$ & $7(24.1)$ & 0.586 \\
\hline $7(41.2)$ & $3(10.0)$ & 0.017 & $8(28.6)$ & $2(10.5)$ & 0.131 & $6(33.3)$ & $4(13.8)$ & 0.111 \\
\hline $5(29.4)$ & $5(16.7)$ & 0.253 & $6(21.4)$ & $4(21.1)$ & 0.634 & $5(27.8)$ & $5(17.2)$ & 0.308 \\
\hline $4(23.5)$ & $1(3.3)$ & 0.051 & $5(17.9)$ & $0(0.0)$ & 0.064 & $3(16.7)$ & $2(6.9)$ & 0.279 \\
\hline $9(52.9)$ & $15(50.0)$ & 0.544 & $17(60.7)$ & $7(36.8)$ & 0.095 & $15(83.3)$ & $9(31.0)$ & 0.001 \\
\hline $6(35.3)$ & $5(16.7)$ & 0.138 & $9(32.1)$ & $2(10.5)$ & 0.083 & 7 (38.9) & $4(13.8)$ & 0.054 \\
\hline $5(29.4)$ & $1(3.3)$ & 0.018 & $5(17.9)$ & $1(5.3)$ & 0.209 & $4(22.2)$ & $2(6.9)$ & 0.141 \\
\hline $3(17.6)$ & $11(36.7)$ & 0.150 & $6(21.4)$ & $8(42.1)$ & 0.116 & $4(22.2)$ & $10(34.5)$ & 0.289 \\
\hline $1.5 \pm 1.2$ & $1.2 \pm 1.4$ & 0.238 & $1.6 \pm 1.3$ & $0.9 \pm 1.4$ & 0.045 & $1.8 \pm 1.1$ & $1.0 \pm 1.4$ & 0.010 \\
\hline $1.0(0-4)$ & $0.5(0-5)$ & & $0.0(0-4)$ & $0.0(0-5)$ & & $2.0(0-4)$ & $0.0(0-5)$ & \\
\hline $1.3 \pm 1.1$ & $1.2 \pm 0.9$ & 0.831 & $1.4 \pm 1.1$ & $1.1 \pm 0.8$ & 0.300 & $1.6 \pm 1.2$ & $1.0 \pm 0.7$ & 0.124 \\
\hline $1.0(0-4)$ & $1.0(0-3)$ & & $0.0(0-4)$ & $1.0(0-3)$ & & $2.0(0-4)$ & $1.0(0-3)$ & \\
\hline $1.2 \pm 0.8$ & $0.5 \pm 0.7$ & 0.003 & $1.0 \pm 0.8$ & $0.5 \pm 0.7$ & 0.037 & $1.0 \pm 0.9$ & $0.6 \pm 0.7$ & 0.150 \\
\hline $1.0(0-3)$ & $0.0(0-2)$ & & $0.0(0-3)$ & $0.0(0-2)$ & & $1.0(0-3)$ & $0.0(0-2)$ & \\
\hline $0.8 \pm 0.7$ & $0.6 \pm 0.6$ & 0.222 & $0.7 \pm 0.8$ & $0.6 \pm 0.5$ & 0.724 & $0.8 \pm 0.8$ & $0.6 \pm 0.6$ & 0.232 \\
\hline $1.0(0-3)$ & $0.5(0-2)$ & & $0.0(0-3)$ & $1.0(0-1)$ & & $1.0(0-3)$ & $1.0(0-2)$ & \\
\hline
\end{tabular}

regard to physical frailty. However, the non-housebound group scored significantly higher in the subitem of grip strength.

1-2) Mental frailty: There were no significant differences between the housebound and non-housebound groups for people with mental frailty.

1-3) Social frailty: There were no significant differences between the housebound and non-housebound groups for people with social frailty.

2) TFI frailty

There were 18 (38.3\%) and 13 subjects (27.7\%), respectively, in the housebound and non-housebound groups with TFI frailty; their mean scores for TFI frailty were $4.7 \pm 2.3$ points and $3.6 \pm 2.1$ points respectively, indicating a significant difference.
The correlation between each item on the basic checklist and frailty in the housebound group

Table 3 shows each item on the basic checklist that is applicable to the groups with and without frailty in the housebound group.

1) Overall frailty

Many people without total frailty visited friends' homes, discussed matters with their friends and family, were not anxious about falls, obtained low scores on lifestyle, and had low scores on nutritional status and oral function.

Many people without TFI frailty went out by themselves, visited their friends' homes, discussed matters with their friends and family, were not anxious about falls, had not experienced decreases in the number of outings over the previous year, and obtained low scores on lifestyle. 


\section{2) Physical frailty}

There were no significant differences between physical frail and non-physical frail persons in any items on the basic checklist for physical frailty.

3) Mental frailty

Many people without mental frailty visited their friends' homes, discussed matters with their friends and family, were not anxious about falls, and had low scores on lifestyle.

4) Social frailty

Many people without social frailty discussed matters with their friends and family, did not have increased difficulty eating hard food, looked up telephone numbers and made telephone calls, and had low scores on nutritional status and oral function. Many people with social frailty had a habit of walking for about 15 minutes.

\section{Discussion}

\section{Correlation between being housebound and frailty}

There was no difference between the housebound and non-housebound groups in the incidence of frailty, including TFI and physical, mental, and social frailty. However, the housebound group obtained a higher TFI frailty score and a lower grip strength value than did the non-housebound group. Given that reports indicate that housebound elderly women are at a higher risk of requiring nursing care $^{5,24)}$, and that the mortality rate increases after 2 years ${ }^{24)}$, we expected houseboundedness to correlate with frailty, but the results of this study did not support that premise.

In this study, being housebound was defined and evaluated only based on the frequency of outings. However, when we compared the applicable items on the basic checklist for the housebound elderly groups with and without TFI frailty, many subjects in the frailty group answered that the frequency of outings had decreased compared to the previous year. Previously, housebound types were classified based on the capacity for movement; however, it has been pointed out that these types have different characteristics ${ }^{2}$, and that a reduction in the frequency of outings is a risk factor for requiring nursing care ${ }^{25)}$. This suggests that it is necessary to consider the continued duration of houseboundedness, as well as any changes in the frequency of outings, when evaluating whether a person is housebound. This study was conducted by medical professionals in the form of a home visit surveys, and it is estimated that people with a high level of awareness regarding about own health consented to participate in the study. Therefore, even the housebound participants in this study may have had a comparatively high level of awareness of health. Future studies must investigate these groups with stricter selection criteria for housebound elderly persons.
In this study, there were differences between the housebound and non-housebound groups in the TFI frailty score and grip strength. In a previous study ${ }^{26)}$, many people with low grip strength had difficulties with daily walking and going up and down stairs, and many had experienced falls. In addition, these individuals were reported to have reduced ability for physical activity. Moreover, people with reduced grip strength were predicted to not only have reduced grip strength, but also an overall reduction in muscle strength and reduced ability for physical activity. Given the differences observed in these two indicators, we estimated that housebound elderly persons had reduced muscle strength and ability for physical activity, compared to non-housebound elderly persons; these could likely result in frailty.

In the analysis of applicable items on the basic checklist for the housebound group, many people in the group with social frailty had scored poorly on nutritional status and oral function. Previous studies have also reported that malnutrition in elderly; community-dwelling persons are related to social isolation ${ }^{27)}$; the current study results suggest the same for housebound elderly persons.

A significant difference was also observed in the lifestyle scores of the groups with frailty and TFI frailty and the groups without frailty and TFI frailty, which suggests that people who manifest frailty have lower levels of lifestyle function. When compared to people without frailty, many more people who manifested frailty subscribed life function items on the basic checklist, including: visiting friends' homes and discussing matters with friends and family. Based on a previous study ${ }^{28}$, informal interaction with others, such as telephoning friends and talking to family members, inhibits depression. This was also reflected in the results of this study on housebound elderly persons. This suggests that personal contact with friends and family affects the health of housebound elderly persons who seldom leave the house.

Furthermore, the incidence of frailty was low in people without anxiety regarding falls. Past reports have shown that frailty is a risk factor for falls ${ }^{29}$, and that anxiety over falling causes mild dementia ${ }^{30)}$ and reduces ADL and social participation ${ }^{31}$. Falls are considered to be a factor in the frailty cycle $^{32)}$ that eventually reduces a person's activity level, and it is a continuous chain leading to frailty. Based on the results of this study, housebound elderly persons' anxiety regarding falls reduces their living activities and cognitive function, as well as social participation, which then leads to overall frailty.

Many housebound elderly persons had few opportunities to interact with the world outside their homes, which suggests that it is difficult to ascertain the actual situation of elderly persons who require not only medical interven- 
tion, but also intervention for their situation. However, the incidence of frailty was significantly high in people with high scores on lifestyle function on the basic checklist; this suggests that it may be easy to identify those manifesting frailty among housebound elderly persons, using the basic checklist.

\section{Limitations of this study}

One of the limitations of this study was that it was crosssectional; so, a causal association was not determined. Since factors involved in houseboundedness, details regarding the frequency of outings, the duration of houseboundedness, and environmental/seasonal conditions were not ascertained, housebound elderly persons could not be strictly identified and the housebound group may have included people with different characteristics. Conducting a detailed investigation of this group, including the background factors to becoming housebound, may enable a more accurate understanding of the situation, as well as clarification of the related factors.

\section{Conclusion}

This study found no correlation between elderly people being housebound and with physical, mental, social, and overall frailty. However, non-housebound elderly persons obtained lower TFI frailty score and higher grip strength value, compared to housebound elderly persons. This suggests that being housebound may lead to frailty. On the other hand, individual interaction with family and friends and a lack of anxiety regarding falls ostensibly correlate with the prevention of frailty in housebound elderly persons. The results of the study also suggest that the basic checklist may be effective for ascertaining the actual situation of housebound elderly persons who may be manifesting frailty.

Conflict of interest: There are no conflicts of interest to declare.

\section{Acknowledgements}

We would like to express our gratitude to all the participants in this study for their invaluable contributions.

\section{References}

1. Cabinet Office Heisei. 27 nendo ban korei syakai hakusyokoreika no genzyo to syoraizo. 2016 (in Japanese) http:// www8.cao.go.jp/kourei/whitepaper/w-2015/zenbun/27pdf index.html Accessed: 2016.3.6.

2. Shinkai S, Fujita K, Fujiwara Y, et al. Predictors for the onset of different types of homeboundness among community-liv- ing older adults: two-year prospective study. Nippon Koshu Eisei Zasshi 2005; 52: 874-885 (in Japanese). [Medline]

3. Shinkai S, Fujita K, Fujiwara Y, et al. Prognosis of different types of homeboundness among community-living older adults: two-year prospective study. Nippon Koshu Eisei Zasshi 2005; 52: 627-638 (in Japanese). [Medline]

4. Kimura H. Kyojyaku koureisya ni okeru syukannteki tojikomori no shintaiteki/shakaiteki tokucyou. Nihon Hoken Hukusi Gakkaisi 2007; 14: 43-50 (in Japanse).

5. Yokokawa H, Yasumura S, Tanno K, et al. Association between homebound status and newly certified need of care among elderly in a rural community: the Iwate-Kenpoku cohort (Iwate-KENCO) study. Nippon Ronen Igakkai Zasshi 2009; 46: 447-457 (in Japanese, Abstract in English). [Medline] [CrossRef]

6. Nihon Ronen Igakukai. Hureiru ni kansuru nihon rounen igakukai kara no sute-tomento (in Japanese). http://www.jpngeriat-soc.or.jp/index.html, Accessed: 2016.3.6.

7. Gobbens RJ, Luijkx KG, Wijnen-Sponselee MT, et al. Towards an integral conceptual model of frailty. J Nutr Health Aging 2010; 14: 175-181. [Medline] [CrossRef]

8. Boers M, Cruz Jentoft AJ. A new concept of health can improve the definition of frailty. Calcif Tissue Int 2015; 97: 429-431 [CrossRef]. [Medline]

9. Op het Veld LP, van Rossum E, Kempen GI, et al. Fried phenotype of frailty: cross-sectional comparison of three frailty stages on various health domains. BMC Geriatr 2015; 15: 77. [Medline] [CrossRef]

10. Fried LP, Tangen CM, Walston J, et al. Cardiovascular Health Study Collaborative Research Group. Frailty in older adults: evidence for a phenotype. J Gerontol A Biol Sci Med Sci 2001; 56: M146-M156. [Medline] [CrossRef]

11. Drey M, Pfeifer K, Sieber CC, et al. The Fried frailty criteria as inclusion criteria for a randomized controlled trial: personal experience and literature review. Gerontology 2011; 57: 11-18. [Medline] [CrossRef]

12. Espinoza SE, Hazuda HP. Frailty prevalence and neighborhood residence in older Mexican Americans: the San Antonio longitudinal study of aging. J Am Geriatr Soc 2015; 63: 106-111 (JAGS). [Medline] [CrossRef]

13. Hoogendijk EO, van Hout HP, van der Horst HE, et al. Do psychosocial resources modify the effects of frailty on functional decline and mortality? J Psychosom Res 2014; 77: 547-551. [Medline] [CrossRef]

14. Gobbens RJ, van Assen MA, Luijkx KG, et al. The Tilburg Frailty Indicator: psychometric properties. J Am Med Dir Assoc 2010; 11: 344-355. [Medline] [CrossRef]

15. Koyano W. Tiiki ni okeru katudou nouryoku no sokutei roukensiki katudou nouryoku sihyou no kaihatu-. Nihon Kosyu Eisei Zassi 1987; 34: 109-114 (in Japanese).

16. Belloc NB, Breslow L. Relationship of physical health status and health practices. Prev Med 1972; 1: 409-421. [Medline] [CrossRef]

17. Shinkai S, Watanabe S, Yoshida H, et al. Kaigo yobou cheku risuto no kyojaku sihyou to site no datousei no kensyou. Ni- 
hon Kosyu Eisei Zassi 2013; 60: 262-274 (in Japanese).

18. Suzuki H. Montreal Cognitive Assessment (MoCA) no nihongoban sakusei to sono yukousei ni tuite (tokusyu keido nincisho wo sukuriningu suru tam no sinkei sinriteki kensa). Rounen Seisin Igaku Zassi 2010; 21: 198-202 (in Japanese).

19. Yatomi N. Nihon ni okeru ronenyo utu suke-ru (GDS) tansyukuban no insi kozo to komoku tokusei no kento. Ronen Syakai Kagaku 1994; 16: 29-36 (in Japanese).

20. Watanabe M, Imagawa T. Factor structure of the short form of the Geriatric Depression Scale (GDS): Reliability, validity and cuto points. Jpn J Pers 2013; 22: 193-197 (in Japanese, Abstract in English).

21. Ozeki Y, Haraguchi M, Tsuda A. Daigakusei no sinriteki sutoresu katei no kyobunsan bunseki kozo. Kenko Sinrigaku Kenkyu 1994; 7: 20-36 (in Japanese).

22. Kurimoto A, Awata S, Ohkubo T, et al. Nihongo ban Lubben Social Network Scale tansyuku ban no sakusei to sinraisei oyobi datosei no kento. Nihon Ronen Igakukai Zassi 2011; 48: 149-157 (in Japanese). [CrossRef]

23. Kosei rodo syo. Kaigo hoken manyuaru (Kaiteiban:Heisei 24 nen san gatu) ni tuite, 2016 (in Japanese). http://www.mhlw. go.jp/topics/2009/05/tp0501-1.html Accessed: 2016.3.10.

24. Herr M, Latouche A, Ankri J. Homebound status increases death risk within two years in the elderly: results from a national longitudinal survey. Arch Gerontol Geriatr 2013; 56: 258-264. [Medline] [CrossRef]

25. Katsura T, Fujimoto M, Shizawa M, et al. A retrospective cohort study on the risk assessment of newly certificated longterm care need of elderly individuals in a community: Basic checklist and specific health checkup. J Rural Med 2017; 12: 68-84. [Medline] [CrossRef]
26. Kuh D, Bassey EJ, Butterworth S, et al. Musculoskeletal Study Team. Grip strength, postural control, and functional leg power in a representative cohort of British men and women: associations with physical activity, health status, and socioeconomic conditions. J Gerontol A Biol Sci Med Sci 2005; 60: 224-231. [Medline] [CrossRef]

27. Arai K, Sakakibara H. Tosi koei zyutaku ni okeru koreisya no teieiyo to syakaiteki koritu zyotai tono kanren. Nihon Kosyu Eisei Zassi 2015; 62: 379-389 (in Japanese).

28. Lee SH, Kim YB. Which type of social activities decrease depression in the elderly? An analysis of a population-based study in South Korea. Iran J Public Health 2014; 43: 903-912. [Medline]

29. Kojima G, Kendrick D, Skelton DA, et al. Frailty predicts short-term incidence of future falls among British community-dwelling older people: a prospective cohort study nested within a randomised controlled trial. BMC Geriatr 2015; 15: 155 [CrossRef]. [Medline]

30. Uemura K, Shimada H, Makizako H, et al. Effects of mild cognitive impairment on the development of fear of falling in older adults: A prospective cohort study. JAMDA 2015; 16: $00.4 \mathrm{e} 9-1104 \mathrm{e} 13$.

31. van der Meulen E, Zijlstra GA, Ambergen T, et al. Effect of fall-related concerns on physical, mental, and social function in community-dwelling older adults: a prospective cohort study. J Am Geriatr Soc 2014; 62: 2333-2338 10.1111/ jgs.13083. [Medline]

32. Xue QL, Bandeen-Roche K, Varadhan R, et al. Initial manifestations of frailty criteria and the development of frailty phenotype in the Women's Health and Aging Study II. J Gerontol A Biol Sci Med Sci 2008; 63: 984-990. [Medline] [CrossRef] 